\title{
Arsenic contamination levels in drinking water sources in mining areas in Lake Victoria Basin, Tanzania, and its removal using stabilized ferralsols
}

\author{
Gabriel R. KASSENGA * and Rubhera R. MATO \\ Department of Environmental Science and Management, Ardhi University (ARU), P. O. Box 35176, \\ Dar es Salaam, Tanzania. \\ "Corresponding author, E-mail: kassengagr@yahoo.com, kassenga@aru.ac.tz, Tel. (255 022) 2771272, \\ 2775004 (Office), Fax: (255 022) 2775448, 2775479
}

\begin{abstract}
Arsenic contamination in drinking water is a public health problem all over the World especially in mining areas. The study herein reported assessed the concentration levels of arsenic in some drinking water sources in the mining areas in the Lake Victoria Basin and investigated the potential for its removal by adsorption using stabilized ferralsols. Randomly collected samples from drinking water sources were analysed for arsenic, phosphorus, iron and $\mathrm{pH}$. Arsenic was detected in 58\% of water sources surveyed and $41 \%$ of them had arsenic levels equal to or exceeding the Tanzania Drinking Water Quality Standards threshold value of 10 $\mathrm{ppb}$. Arsenic mobilization is suspected to be due to oxidation of arsenopyrite after exposure of the ore to the air partly due to mining activities. Laboratory experiments have shown that adsorption using stabilized ferralsols (1:1 mixture of Portland cement and ferralsols on dry weight basis) is capable of removing up to $97 \%$ of arsenic independent of water $\mathrm{pH}$ and initial contaminant concentrations used during the study. In view of this, adsorption using stabilized ferralsols may be considered to be a promising technology for removing arsenic from drinking water.
\end{abstract}

(C) 2008 International Formulae Group. All rights reserved.

Keywords: Arsenopyrite, Portland cement, Adsorption isotherms, Groundwater, Efficiency.

\section{INTRODUCTION}

Arsenic is a highly toxic metalloid that is brittle, crystalline, odourless and tasteless in its elemental form (Kassenga, 2003). Naturally, arsenic occurs primarily as arsenopyrite (FeAsS), which is the most abundant arsenic mineral, dominantly in mineral veins (Halsey, 2000). Smedley and Kinniburgh (2002) describe different manifestations of arsenic which are basically inorganic and organic forms; inorganic species are mainly arsenite, As(III), and arsenate, $\mathrm{As}(\mathrm{V})$. The inorganic species of arsenic (arsenite and arsenate) are the most important species with relevance to toxicity in humans (Halsey, 2000; Kassenga, 2003). Consequentially, these two species have been the centre of focus of many arsenic researches
(Korte and Fernando, 1991; Vance, 1995; Halsey, 2000) including the present study.

The significance of arsenic speciation is based on toxicity and remedial capability (Vance, 1995). Arsenite is the most toxic of all the species of arsenic. Arsenite is about 60 times more poisonous than arsenate and 70 times more toxic than the methylated species (Korte and Fernando, 1991). Besides, as far as arsenic removal in contaminated water is concerned, arsenite is difficult to be removed by using many conventional and innovative remediation techniques (Korte and Fernando, 1991; Halsey, 2000).

The World Health Organization (WHO) (2001) has set the International Drinking Water Guideline for arsenic at 10 ppb. This is a strict maximum value because of high toxicity caused by this chemical. The 
major early manifestations due to acute arsenic poisoning include burning and dryness of the mouth and throat, dysphasia, colicky abnormal pain, projectile vomiting, profuse diarrhoea, and hematuria (Kassenga, 2003). The muscular cramps, facial edema and cardiac abnormalities, shock can develop rapidly as a result of dehydration (Jain and Ali, 2000).

According to Smith et al. (2000), approximately 20 million people are thought to be exposed to arsenic poisoning and another 50 million are considered to be at risk of arsenic poisoning after the installation of over 4 million tube wells in Bangladesh. Arsenic levels higher than $50 \mathrm{ppb}$ are common and levels as high as 2,000 ppb have been reported and generally, many wells were observed to exceed the WHO drinking water standard of $10 \mathrm{ppb}$ (Smith et al., 2000).

In Ghana, high arsenic concentrations have been noted in soils and river waters close to the gold mining activity (Smedley, 1996). This is because gold containing ore is associated with sulphide mineralization, particularly arsenopyrite (Smedley and Kinniburgh, 2002). Arsenic contamination from mining activities has been identified in numerous areas of the USA, many of which have been summarized in Welch et al. (2000). According to Welch et al., (2000), groundwater from some areas has been reported to have very high arsenic concentrations of up to $48,000 \mathrm{ppb}$.

The Lake Victoria Basin is the leading gold producing area in Tanzania. There is a number of goldfields in the area (collectively known as Lake Victoria Goldfields) and they are located in the Archean Nyanzian greenstone belt east and south of Lake Victoria in northwest Tanzania (Department of Geology, 1994). A short term assessment study on mercury and other heavy metal pollution in gold mining areas around Lake Victoria conducted in 1994 by Department of Geology of the University of Dar es Salaam, Tanzania showed the presence of arsenic with concentrations, which ranged from 0.5 to 379 $\mathrm{ppb}$ in some water sources (Department of Geology, 1994). Suspected source of arsenic pollution in the sediments and water was identified to be oxidation of arsenopyrite in mine tailings dumped into the rivers during gold panning.
Arsenic toxicity has no known effective treatment, but drinking of arsenic free water can help arsenic affected people at early stage of ailment to get rid of the symptoms of arsenic toxicity. Therefore, the most important measure needed is to prevent further exposure of population by providing them with arsenicfree safe drinking water. There exist a number of treatment processes to remove arsenic from drinking water including sulphide precipitation, co-precipitation with iron and metal hydroxides, coagulation and adsorption processes. Methods, which are usually used for removal of arsenic from drinking water in developed countries such as lime softening, ion exchange resins, membrane methods and activated alumina (Johnston and Heijnen, 2001) are often too expensive to be used in developing countries. Socio-economic conditions of Tanzania and other less developed countries demand low-cost as well as small-scale treatment systems that could be implemented in the rural areas at household or community levels. Thus, there is an urgent need to develop simple to use and cost efficient treatment technologies capable of removing arsenic from drinking water.

The general objective of the study for which this paper was prepared was to conduct a rapid assessment on the contamination levels of arsenic in drinking water sources in mining areas of the Lake Victoria Basin in Tanzania and to investigate the potential of stabilized ferralsols in removal of the contaminant by adsorption for future design of household and small community water treatment systems. Specifically, the study quantified the concentration levels of arsenic in drinking water sources and determined the arsenic adsorption isotherms of stabilized ferralsols as well as the removal performance of the adsorbent focusing on the influence of water $\mathrm{pH}$ and initial arsenic concentration.

\section{MATERIALS AND METHODS \\ Study Area}

Field studies involved onsite measurements of concentrations of arsenic, iron and phosphorus in drinking water sources. These studies were conducted in the Lake Victoria Basin in Tanzania, which covers some parts of the regions of Shinyanga, Mwanza, and Mara. Water sources sampled were specifically located in districts 
of Bariadi, Maswa, Meatu, Kahama and Bukombe in Shinyanga region, Musoma, Buhemba, and Serengeti in Mara region and Mwanza urban, Sengerema, Geita, and Kwimba in Mwanza region as shown in Figure 1. The total population in the sampled districts is around 4.2 million people, which is approximately $12 \%$ of the entire population of the country (URT, 2002).

\section{Geochemical Modelling}

The influence of $\mathrm{pH}$, ferric iron and phosphorus as well as other geochemical conditions on speciation of arsenic were analysed using PHREEQC computer model (Version 2 for Windows). PHREEQC is a computer program that is designed to perform a wide variety of low-temperature aqueous geochemical calculations. The model is based on an ion-association aqueous model and has capabilities for (i) speciation and saturationindex calculations; (ii) batch-reaction; and, (iii) one-dimensional transport calculations involving reversible reactions (Parkhurst and Appelo, 1999). Model inputs were reactions of arsenic in aquifer media, $\mathrm{pH}$, concentrations of iron, phosphate and arsenic whereas the outputs were concentrations of various complexes of arsenic.

\section{Laboratory Experiments \\ Materials}

a) Chemicals and reagents

Neat solution of arsenic trioxide $\mathrm{As}_{2} \mathrm{O}_{3}$, $(1 \mathrm{mg} / \mathrm{mL})$ in $0.5 \mathrm{M} / \mathrm{L} \mathrm{HCl}$ (BDH Chemicals Ltd., Leicestershire, UK) was used to prepare stock solutions of arsenic. Iron and phosphorus standard solutions were obtained from Hach Co. (Loveland, CO). Other chemicals used in this study such as $\mathrm{HNO}_{3}$, and $\mathrm{NaOH}$ were reagent grade and most of them were purchased from BDH Chemicals Ltd. (Leicestershire, UK).

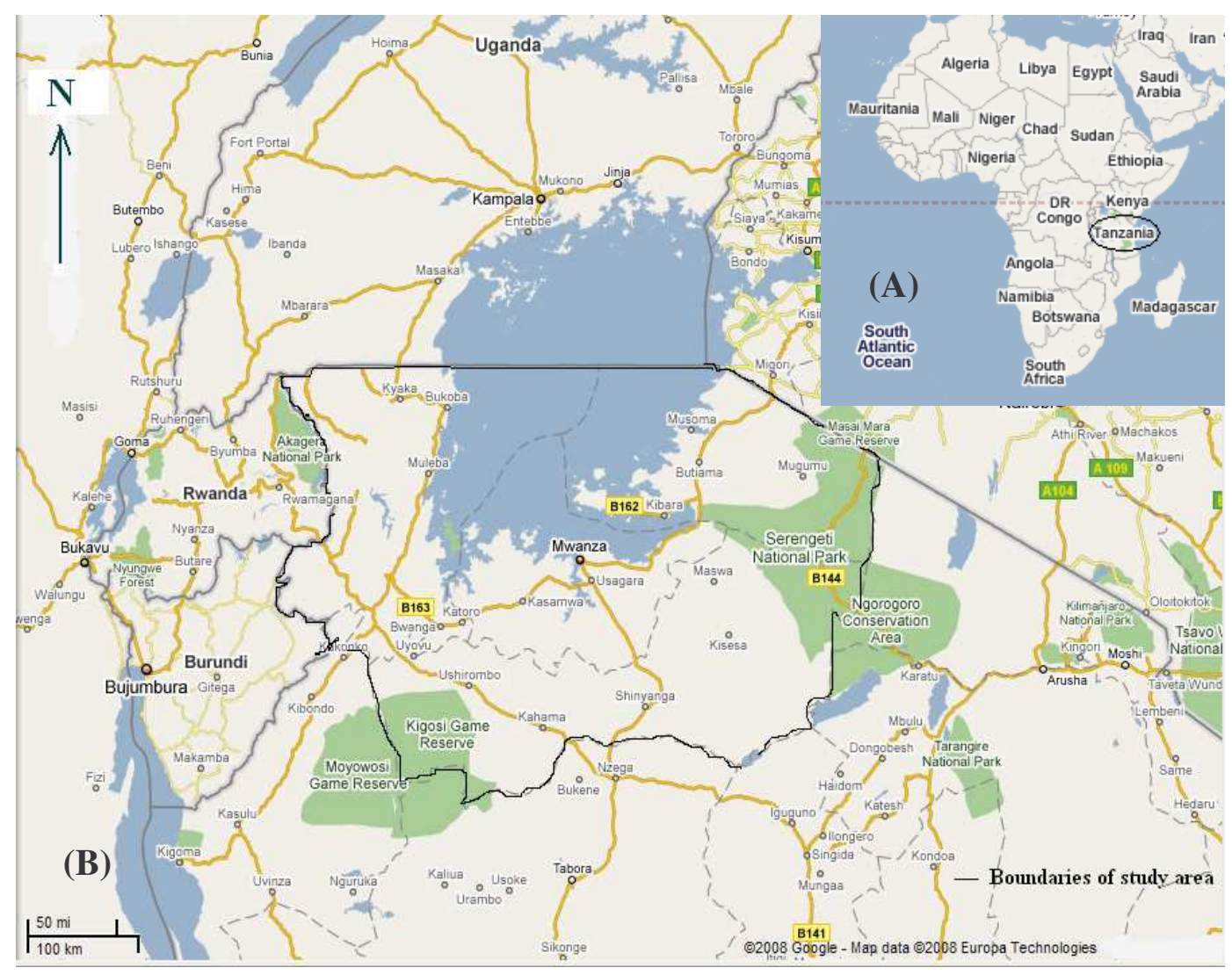

Figure 1: Location maps of Tanzania in Africa (A) and the study area (B). 
b) Preparation of adsorbent (stabilized ferralsols)

Ferralsols used in this experiment was collected and prepared according to the modified procedures specified in Kundu et al. (2004). In brief, ferralsols was soaked and stirred in distilled water and then left in quiescence condition for 1 hour after which, suspended organic matter were removed. The ferralsols was then dried for 24 hours at room temperature of $25 \pm 1{ }^{\circ} \mathrm{C}$.

Three hundreds grams $(300 \mathrm{~g})$ of ferralsols and $300 \mathrm{~g}$ (ratio of $1: 1$ by dry weight) of commercially available Portland cement (Tanzania Portland Cement Ltd, Dar es Salaam, Tanzania) were mixed with sufficient amount of distilled water to form a homogeneous slurry mixture. The slurry mixture was then stored for 72 hours in a plastic container at room temperature $(25 \pm 1$ ${ }^{\circ} \mathrm{C}$ ) for hardening.

After the hardened stabilized ferralsols was completely air-dried, it was broken into particles of approximately $300 \mathrm{~mm}$ using a sledgehammer. For further stabilization of bonds between cement and ferralsols, the granules were submerged in water for 96 hours.

The granules were further reduced in size using a sledgehammer. The required sizes of stabilized ferralsols were obtained by sieving whereby two sieve sizes of $1.5 \mathrm{~mm}$ and $3.0 \mathrm{~mm}$ were used to arrive at particle sizes, which ranged between 1.5 and $3.0 \mathrm{~mm}$. The granules were finally oven-dried for 24 hours between 100 and $110{ }^{\circ} \mathrm{C}$ before use.

\section{Adsorption experiments}

The main objective of adsorption experiments was to determine the capacity of stabilized ferrasols in adsorbing arsenic under various $\mathrm{pH}$ conditions. Adsorption experiments were done using tightly covered $1000 \mathrm{~mL}$ glass beakers containing $500 \mathrm{~mL}$ of arsenic solution with varying concentrations and $10 \mathrm{~g}$ of ferralsols $(20 \mathrm{~g} / \mathrm{L})$. pH of arsenic solution was adjusted by adding $0.1 \mathrm{~N} \mathrm{HCl}$ or $1 \mathrm{M} \mathrm{NaOH}$ to obtain $\mathrm{pH}$ values of $4,5,6,7,8$, and 9 (Standard error for each measured $\mathrm{pH}$ value was \pm 0.1 ). For each $\mathrm{pH}$ value, three experiments were performed for a total of 15 isotherm points. Isotherm points were generated by diluting the arsenic solution with an electrolyte solution (0.01 $\left.\mathrm{M} \mathrm{CaCl}_{2}\right)$ using dilutions of $1: 1,1: 2,1: 4,1: 8$ and $1: 16$ to obtain concentrations of 20,10, 5, 2.5 and $1.25 \mathrm{mg} / \mathrm{L}$. Control experiments were also conducted for each $\mathrm{pH}$ using the adsorbents and distilled water.

Contents of beakers were thoroughly mixed to facilitate adsorption by stirring at 25 $\pm 1{ }^{\circ} \mathrm{C}$ for 8 hours at 70 revolutions per minute using the jar tester $\left(\mathrm{PB}-700^{\mathrm{TM}}\right.$ Standard JarTester, Phipps \& Bird, Inc., Richmond, Virginia), centrifuged and the clear supernatant analyzed for arsenic using Atomic Absorption Hydride System (HC 3000).

\section{Arsenic removal efficiency}

Assessment of arsenic removal efficiency by adsorption onto stabilized ferralsols matrix at different $\mathrm{pH}$ values $(4,5$, 6, 7, 8 and 9) and arsenic concentrations of 2.5, 5.0, 10.0 and $20.0 \mathrm{mg} / \mathrm{L}$ was conducted in triplicate by batch experiments. Batch experiments were conducted in a similar manner as adsorption experiments as described above.

\section{Analytical methods}

Field analysis of arsenic was done using Arsenic Test Kit (Hach Company, Loveland, CO), which has a detection limit of $5 \mathrm{ppb}$. Aqueous concentrations of ferrous iron and phosphorus were analysed using a colorimetric method with a portable spectrophotometer (DR 2010; Hach Co., Loveland, CO). Global Positioning System (GPS) was used to record the locations of the sampling points.

Chemical compositions of ferralsols and stabilized ferralsols were measured using Sequential X-ray Spectrometer (SRS 300) from Siemens equipped with a Rh 65 endwindow tube (Beryllium, $125 \mu \mathrm{m}$, using the Rh-. L-line). Sample preparation involved mixing $5 \mathrm{~g}$ of pulverized sample with $8 \mathrm{~g}$ boric acid which, was used as a binder. The mixture was then subjected to a pressure treatment of $2 \mathrm{kN} / \mathrm{m}^{2}$ for one minute to obtain pellets of the sample with a thickness of 4 mm. Pellets were finally analysed both qualitatively and quantitatively using the Sequential X-ray Spectrometer.

Laboratory analysis of arsenic was done using Atomic Absorption Hydride System (HC 3000) from GBS Scientific Equipment (Arlington Heights, IL). The detection limit of this method is $0.5 \mathrm{ppb}$. 


\section{Computational Framework Adsorption efficiency}

The adsorbed concentration of arsenic was calculated from the measured equilibrium concentrations as:

$q_{e}=\left(c_{i}-c_{e}\right) \times \frac{V}{m}$

where $q_{e}(\mathrm{mg} / \mathrm{kg})$ is adsorbed concentration; $c_{i}$ $(\mathrm{mg} / \mathrm{L})$ is initial arsenite concentration; $c_{e}$ $(\mathrm{mg} / \mathrm{L})$ equilibrium concentration; $V(\mathrm{~L})$ is volume of the solution; and, $m(\mathrm{~kg})$ is weight of the stabilised ferralsols.

Percentage removal of arsenic was calculated from the measured equilibrium concentrations as follows:

$\%$ Removalof arsenic $=\frac{c_{i}-c_{e}}{c_{i}} \times 100 \%$

\section{Adsorption Isotherms}

Adsorption of arsenic onto stabilized ferralsols matrix was described using Langmuir and Freundlich models. The linearized version of Langmuir sorption model was used in the present study:

$$
\frac{1}{q_{e}}=\frac{1}{Q_{\max }}+\frac{1}{b Q_{\max }}\left(\frac{1}{C_{e}}\right)
$$

where $q_{e}$ is adsorbed contaminant concentration (mass of contaminant/mass of adsorbent); $b$ is equilibrium constant for the sorption reaction; $C_{e}$ is dissolved contaminant concentration; $Q_{\max }$ is number of sorption sites (maximum amount of sorbed contaminant). Nonlinear isotherms were described by the Freundlich equation:

$q_{e}=k C_{e}^{\frac{1}{n}}$ where $C_{e}$ is the concentration of solute after adsorption; $q_{e}$ is the amount of material adsorbed per unit weight of the adsorbent; $k$ is the distribution coefficient; and, $n$ is the chemical-specific quantity that is determined experimentally.

The Freundlich isotherm is often expressed in its logarithmic form,

$\log q_{e}=\log k+\frac{1}{n} \log C_{e}$

\section{Statistical Analysis}

ANOVA was used to determine if the effect of $\mathrm{pH}$ on removal of arsenic by adsorption onto stabilized ferrasols matrix was indeed significant. The t-test was used to determine the differences in values of coefficient of determination between Freundlich and Langmuir sorption models. The results were considered statistically significant if $P<0.05$.

\section{RESULTS}

Levels of arsenic concentration in drinking water sources

A total of 96 drinking water sources were sampled for analysis of arsenic, iron, phosphorus and $\mathrm{pH}$. Table 1 shows measured concentrations of arsenic in the districts surveyed. It should be noted that Table 1 reports arsenic concentrations only in districts where the contaminant was detected.

\section{Composition of ferralsols and stabilized ferralsols}

The composition of ferralsols and stabilized ferralsols is depicted in Table 2 . Portland cement has the advantage of improving the structure of ferralsols and hence its adsorption capacity by increasing the amount of $\mathrm{CaO}$ (Olisio et al., 2002).

Table 1: Concentrations of arsenic in the surveyed districts

\begin{tabular}{lccc}
\hline $\mathbf{S} / \mathbf{N}$ & District & $\begin{array}{c}\text { Range } \\
(\mathbf{p p b})\end{array}$ & $\begin{array}{c}\text { Mean } \pm \text { Standard Deviation } \\
(\mathbf{p p b})\end{array}$ \\
\hline 1. & Bariadi & $5-10$ & $8.0 \pm 2.7$ \\
\hline 2. & Maswa & $5-70$ & $18.3 \pm 21.14$ \\
\hline 3. & Shinyanga & $5-50$ & $20.7 \pm 20.29$ \\
\hline 4. & Musoma & $5-40$ & $17.2 \pm 12.77$ \\
\hline 5. & Kahama & $5-30$ & $12.5 \pm 11.9$ \\
\hline 6. & Bukombe & $5-10$ & $9.3 \pm 1.88$ \\
\hline 7. & Geita & $5-30$ & $11.3 \pm 7.91$ \\
\hline
\end{tabular}


In the present study, mixing of Portland cement with ferralsols increased the concentration of $\mathrm{CaO}$ by a factor of 47 (Table 2). Furthermore, Table 2 shows that mixing ferrasols with Portland cement reduced the concentration of phosphorus by $33 \%$ relative to un-amended ferrasols. Although mixing reduced the concentration of ferric oxide by $15 \%$ relative to un-amended ferrasols, the amount present in the mixture is still higher than the minimum threshold value of $1.6 \%$, below which impairing of adsorption by phosphorus may occur.

\section{Arsenic removal efficiency of the adsorbent}

The effect of $\mathrm{pH}$ and arsenic concentration on arsenic removal efficiency is presented in Figure 2.

Table 2: Concentration and composition of ferralsols and stabilized ferralsols (mixture of Ferralsols and Portland cement at a ratio of 1:1(w/w)).

\begin{tabular}{lllcc}
\hline Constituent & \multicolumn{2}{c}{$\begin{array}{c}\text { Concentration } \\
\text { (mol/kg dry weight) }\end{array}$} & \multicolumn{2}{c}{ Percent Composition (w/w) } \\
\cline { 2 - 5 } & Mixture & Ferralsols & Mixture & Ferralsols \\
\hline $\mathbf{S i O}_{\mathbf{2}}$ & 24.79 & 53.31 & 29.8 & 64.08 \\
$\mathbf{A l}_{\mathbf{2}} \mathbf{O}_{\mathbf{3}}$ & 6.32 & 11.18 & 12.9 & 22.8 \\
$\mathbf{F e}_{\mathbf{2}} \mathbf{O}_{\mathbf{3}}$ & 1.32 & 1.56 & 4.21 & 4.97 \\
$\mathbf{M n O}$ & 0.06 & 0.07 & 0.09 & 0.10 \\
$\mathbf{M g O}$ & 0.45 & 0.30 & 0.36 & 0.24 \\
$\mathbf{C a O}$ & 30.46 & 0.65 & 34.6 & 0.74 \\
$\mathbf{N a}$ & 0.10 & 0.09 & 0.12 & 0.11 \\
$\mathbf{K}_{\mathbf{2}} \mathbf{O}$ & 0.20 & 0.27 & 0.37 & 0.51 \\
$\mathbf{P}_{\mathbf{2}} \mathbf{O}_{\mathbf{5}}$ & 0.03 & 0.04 & 0.08 & 0.12 \\
$\mathbf{S O}$ & 1.84 & 0.08 & 2.95 & 0.13 \\
$\mathbf{T i O}_{\mathbf{3}}$ & 0.19 & 0.26 & 0.56 & 0.79 \\
$\mathbf{L i O}$ & 30.08 & 11.29 & 13.8 & 5.18 \\
$\mathbf{M i n o r}$ constituents & - & - & 0.09 & 0.03 \\
\hline & \multicolumn{5}{c}{ Total } & $\mathbf{1 0 0 . 0 0}$ & $\mathbf{1 0 0 . 0 0}$ \\
\hline
\end{tabular}

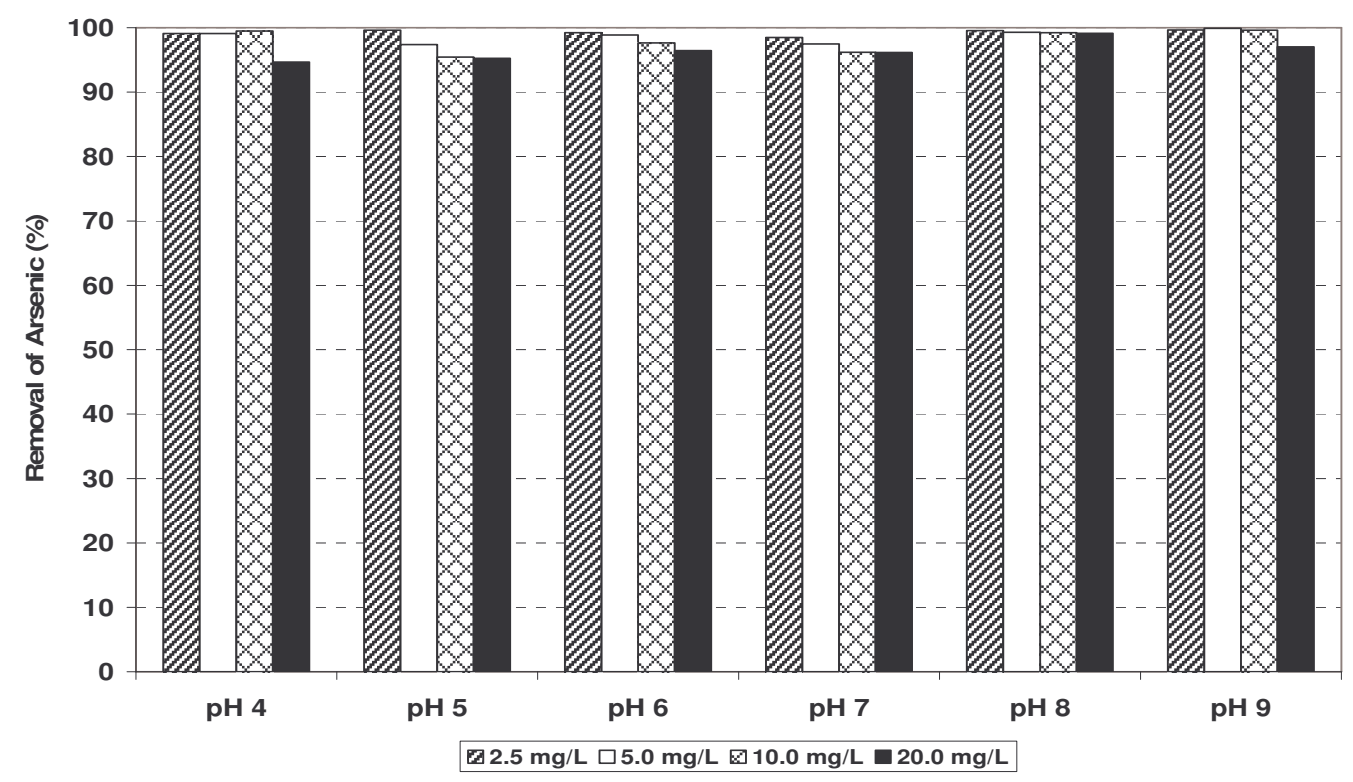

Figure 2: Influence of $\mathrm{pH}$ and arsenic concentration on arsenic removal efficiency 


\section{Adsorption isotherms}

Adsorption isotherms of arsenic are shown in Figure 3 and 4 whereas Table 3 presents parameter values of the Langmuir and Freundlich adsorption models.

\section{DISCUSSION}

\section{Arsenic contamination levels}

Arsenic was detected in $58 \%$ of samples analyzed. In water sources, which tested positive, the observed arsenic concentration values ranged from 5 to $70 \mathrm{ppb}$ (Table 1). Forty-one percent (41\%) of samples analysed had arsenic concentrations exceeding the Tanzania Drinking Water Quality Standards threshold value, which is 10 ppb. Arsenic contamination in the study area was observed to be less serious compared to the situation in other parts of the world reported elsewhere (Welch et al., 2000; Smith et al., 2000). For example, arsenic concentration of $50 \mathrm{ppb}$ is common in Bangladesh and concentrations of up to 2,000 $\mathrm{ppb}$ have been reported in the country (Smith et al., 2000). In USA, concentrations as high as 48,000 ppb were observed in Fairbanks gold mining district in Alaska (Welch et al., 2000). Both America and Bangladesh have the maximum permissible limit of arsenic in drinking water of $50 \mathrm{ppb}$, which is technically and politically acceptable bearing in mind that the levels of the contaminant are high and its spatial distribution is wide.

Ashanti gold mining region in Ghana has higher arsenic concentrations (from 1 to about $140 \mathrm{ppb}$ ) than those observed in the Lake Victoria Basin and no significant health effects have been reported in the region (Smedley, 1996; Mukherjee et al., 2006).

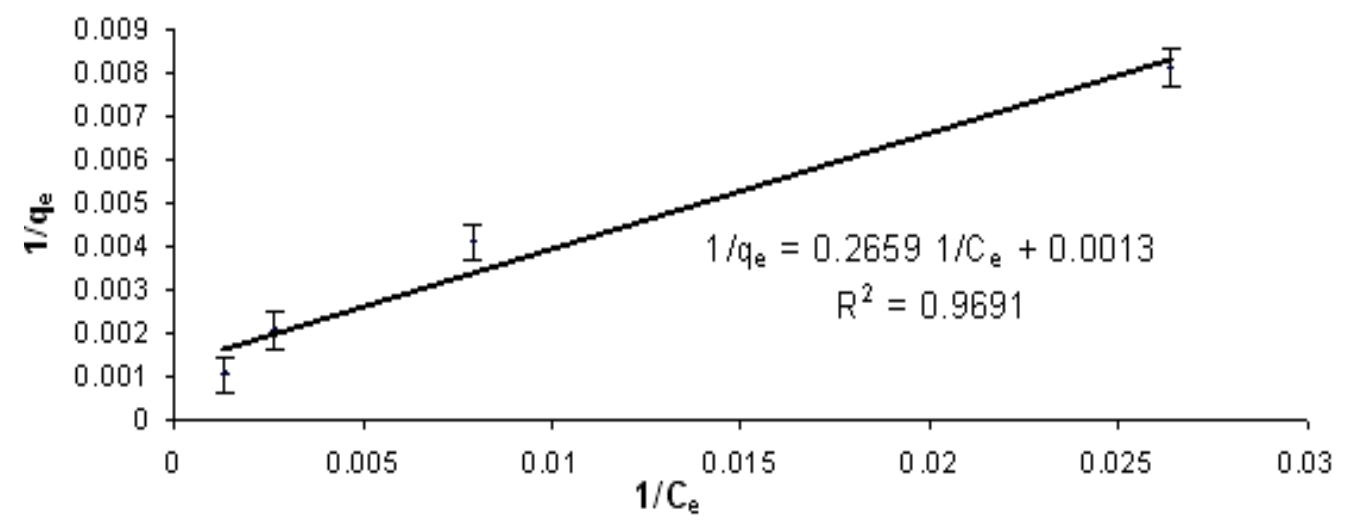

Figure 3: Langmuir Isotherm at $\mathrm{pH} 7$

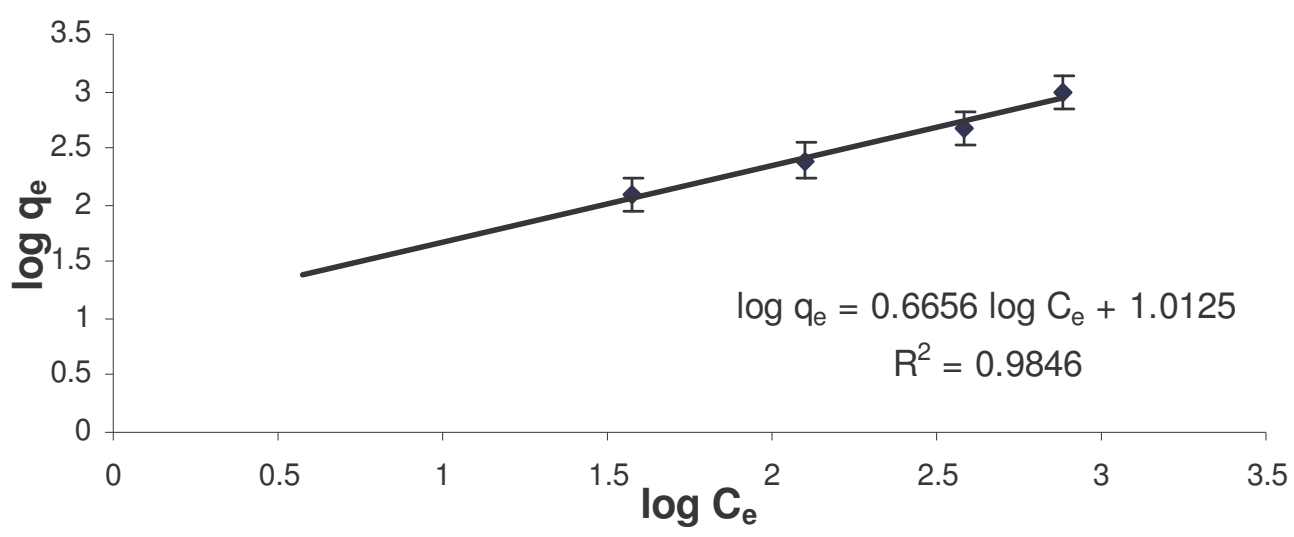

Figure 4: Freundlich Isotherm at pH 7 
Table 3: Values of adsorption parameters.

\begin{tabular}{ccccccccc}
\hline $\mathbf{p H}$ & $\begin{array}{c}\text { Temperature } \\
\left({ }^{\mathbf{0}} \mathbf{C}\right)\end{array}$ & \multicolumn{3}{c}{ Langmuir Constants } & \multicolumn{3}{c}{ Freundlich Constants } \\
\cline { 3 - 9 } & $25 \pm 1$ & $\mathbf{\mathbf { Q } _ { \operatorname { m a x } }}$ & $\mathbf{b}(\boldsymbol{\mu g} / \mathbf{g})$ & $\mathbf{R}^{\mathbf{2}}$ & $\mathbf{k}$ & $\mathbf{1 / n}$ & $\mathbf{n}$ & $\mathbf{R}^{\mathbf{2}}$ \\
\hline $4 \pm 0.1$ & 769 & 0.0087 & 0.890 & 16.66 & 0.58 & 1.7 & 0.980 \\
\hline $5 \pm 0.1$ & $25 \pm 1$ & 625 & 0.0550 & 0.853 & 13.53 & 0.6 & 1.7 & 0.920 \\
\hline $6 \pm 0.1$ & $25 \pm 1$ & 833 & 0.0088 & 0.990 & 15.92 & 0.67 & 1.5 & 0.998 \\
\hline $7 \pm 0.1$ & $25 \pm 1$ & 769 & 0.0049 & 0.971 & 10.29 & 0.67 & 1.5 & 0.980 \\
\hline $8 \pm 0.1$ & $25 \pm 1$ & 769 & 0.0170 & 0.920 & 17.98 & 0.75 & 1.3 & 0.940 \\
\hline $9 \pm 0.1$ & $25 \pm 1$ & 833 & 0.0190 & 0.970 & 16.15 & 0.89 & 1.1 & 0.970 \\
\hline Mean & & 766 & 0.0190 & 0.930 & 15.10 & 0.692 & 1.5 & 0.965 \\
\hline Standard Deviation ( \pm$)$ & 76 & 0.0180 & 0.055 & 2.76 & 0.113 & 0.2 & 0.029 \\
\hline Coefficient of Variation & 0.099 & 0.980 & 0.059 & 0.183 & 0.163 & 0.1 & 0.030 \\
\hline
\end{tabular}

The fact that the observed arsenic concentrations in the study area are inconsequential compared to those reported in other gold mining areas should not be the reason for complacency due to the following reasons:

(i) WHO (2001) asserts that arsenic is carcinogenic even at very low concentrations and the effect is cumulative (even at the WHO guideline of $10 \mathrm{ppb}$, the health risk is still $0.2 \%$ );

(ii) the population in the Lake Victoria basin of around 4.2 million (about $12.4 \%$ of the population of Tanzania) (URT, 2002), which is potentially exposed to arsenic is high and as such even a small risk could be significant. However, the proportion of the population exposed to arsenic in Tanzania is significantly lower compared to that in Bangladesh where the percentage of population exposed to drinking water with arsenic concentration of more than $10 \mathrm{ppb}$ has been reported by Lokuge et al. (2004) to be about $58.8 \%$;

(iii) majority of Tanzanians $(61 \%)$ and especially in rural areas do not have access to safe water and as such they rely on sources with compromised quality including those containing arsenic and other contaminants. It is worth noting that in the Lake Basin more than $67 \%$ of the households live more than a kilometer from a safe drinking water source (URT, 2002); and,

(iv) the lake Basin is generally dry with high evaporation rates (Sutcliffe and Petersen, 2007) thus there is a possibility of concentrating the contaminant in water sources.
Therefore, if left unattended the arsenic contamination problem could sooner than later reach a crisis level.

Arsenate and arsenite, which are arsenic species of significant public health concern, were detected in the sampled water sources in the study area. Observed mean $\mathrm{pH}$ value of samples analysed was $7.58 \pm 1.188$. This $\mathrm{pH}$ value favors the formation of arsenate (specifically $\mathrm{HAsO}_{4}{ }^{2-}$ ) over arsenite. In all samples analysed arsenate was a more predominant species than arsenite. Indeed the output values of the model for speciation of arsenic showed that average concentration of arsenate $(0.19 \mathrm{nMol} / \mathrm{L})$ was six orders of magnitude higher than that of arsenite $(7.2 \times$ $\left.10^{-8} \mathrm{nMol} / \mathrm{L}\right)$. The dominance of arsenate over arsenite is basically because $\mathrm{pH}$ and redox potential of most aquifers favors the formation of the former over the latter (Bhumble and Keefer, 1994; Smedley and Kinniburgh, 2002). Conversely, arsenate, the thermodynamically stable form, generally predominates in oxic surface waters (high redox potential) and moderate $\mathrm{pH}$ range (Bhumble and Keefer, 1994; Smedley and Kinniburgh, 2002). Therefore, the findings of the present study are in agreement with observations made by Smedley and Kinniburgh (2002) and Korte and Fernando (1991) who also observed the predominance of arsenate over arsenite. In addition, low positive Pearson's correlation coefficient $(r=0.1)$ also suggests that formation of the two arsenic species is uncorrelated.

The presence and concentration levels of iron in sampled water sources may provide some clues on mobilization of arsenic in the study area. Major source of arsenic in the 
study area is suspected to be oxidation of arsenopyrite (FeAsS), which is exposed to the air as a result of gold mining activities (Halsey, 2000). Arsenopyrite oxidation releases arsenite (subsequent oxidation to arsenate may occur), sulphate, and ferrous iron, though some oxidation to ferric iron is evident (Halsey, 2000; Smedley and Kinniburgh, 2002). Analytical results of drinking water samples from the study area showed strong positive Pearson's correlation between concentrations of arsenic and iron ( $r$ $=0.9$ ) thus supporting this assertion.

\section{Potential effects of phosphorus on adsorption of arsenic}

The importance of phosphate in analysis of arsenic adsorption stems from the fact that it competes with arsenate for adsorption sites. This competition basically originates from their striking resemblance and it is governed by the Law of Mass Action (Smith et al., 2002). Under normal conditions, phosphate will be preferentially adsorbed onto adsorbent sites by virtue of its higher activity coefficient than that of arsenic (Kassenga, 2003).

According to Smith et al. (2002) the competition between arsenate and phosphates is also affected by the content of oxides of iron in the adsorbent. For an adsorbent with low iron content (less than $100 \mathrm{mmol} / \mathrm{kg}$ dry weight) the minimum threshold concentration of phosphate in water, which may impair arsenic adsorption is about $0.16 \mathrm{mmol} / \mathrm{L}$ (Smith et al., 2002). The average concentration of phosphate in sampled water sources was observed to be $0.15 \mathrm{mmol} / \mathrm{L}$ and the mode was $0.1 \mathrm{mmol} / \mathrm{L}$. Since stabilized ferralsols had iron oxide concentration of $1,560 \mathrm{mmol} / \mathrm{kg}$ (Table 2), which is significantly higher than $100 \mathrm{mmol} / \mathrm{kg}$, the adsorbent should therefore be capable of adsorbing arsenic with minimum impairment of its removal efficiency by phosphate.

\section{Effect of pH on adsorption of arsenic}

The supernatant from the control experiment showed that insignificant concentration of arsenic $(<0.01 \mathrm{ppb})$ was present in either stabilized red soil and/or distilled water; therefore, spiked arsenic trioxide was the only source of arsenic in the reaction vessels.

The influence of $\mathrm{pH}$ on arsenic adsorption was found to be insignificant as Figure 2 shows. Significance of the effect of $\mathrm{pH}$ on arsenic adsorption was evaluated using Analysis of Variance (ANOVA). Indeed the influence of $\mathrm{pH}$ on arsenic adsorption on stabilized ferralsols for all concentrations used during the experiment was found to be insignificant $\left(F_{\text {Crit. }}>F: 2.7728>1.6145\right.$ and $P=0.2068)$ as illustrated in Table 4.

The possible reason for this observation could be that the buffer created by the carbonate ion present in the red soil and Portland cement, negates the dependence of initial $\mathrm{pH}$ on arsenic adsorption as Pogany and Davies (2001) also observed. The mean removal was $98.07 \pm 1.633 \%$ for all $\mathrm{pH}$ values and arsenic concentrations used during the experiment. These results suggest that the adsorbent is capable of removing arsenic effectively over a wide range of $\mathrm{pH}$.

Table 4: ANOVA results.

\begin{tabular}{|c|c|c|c|c|c|c|}
\hline \multicolumn{7}{|l|}{ SUMMARY } \\
\hline Groups & Count & Sum & Average & Variance & & \\
\hline pH 4 & 4 & 392.2825 & 98.07062 & 5.227077 & & \\
\hline pH 5 & 4 & 387.6303 & 96.90758 & 4.184644 & & \\
\hline $\mathrm{pH} 6$ & 4 & 392.1557 & 98.03893 & 1.56918 & & \\
\hline pH 7 & 4 & 388.3189 & 97.07972 & 1.245141 & & \\
\hline $\mathrm{pH} 8$ & 4 & 397.1436 & 99.2859 & 0.034876 & & \\
\hline $\mathrm{pH} 9$ & 4 & 396.1527 & 99.03817 & 1.856862 & & \\
\hline \multicolumn{7}{|l|}{ ANOVA } \\
\hline Source of Variation & $S S$ & $d f$ & $M S$ & $F$ & $P$-value & F crit \\
\hline Between Groups & 18.99449 & 5 & 3.798897 & 1.614516 & 0.206802 & 2.772853 \\
\hline Within Groups & 42.35334 & 18 & 2.352963 & & & \\
\hline Total & 61.34783 & 23 & & & & \\
\hline
\end{tabular}




\section{Adsorption Modeling}

Adsorption of arsenic on stabilized ferralsols was described well with both, Freundlich and Langmuir sorption models as illustrated by plots in Figure 2 and 3 . However, the Freundlich model consistently gave significantly $\left(t_{\text {Crit. }}<t: 2.156<2.571\right.$ and $P=0.041)$ higher coefficient of determination $\left(\mathrm{R}^{2}=0.965 \pm 0.0291\right)$ than Langmuir sorption model $\left(\mathrm{R}^{2}=0.932 \pm 0.0552\right)$ at the concentration range of $1.25-20 \mathrm{mg} / \mathrm{L}$ as shown in Table 2.

This phenomenon could have been caused by the fact that at a high concentration range Langmuir and Freundlich sorption models behave differently. However, at low solute concentration the sorbed concentration increases linearly with increasing solute concentration for both models. The reason for this behaviour is that Langmuir sorption model assumes that there are a limited number of sorption sites whereas the Freundlich sorption model, which is basically a modified Langmuir sorption model assumes that the number of sorption sites is large and infinite relative to the number of contaminant molecules (Wiedemeier, 1996).

It can be observed from Table 2 that the Langmuir sorption model gave lower values of $b(0.0190 \pm 0.0180 \mu \mathrm{g} / \mathrm{g})$, equilibrium constant for the sorption reaction, which signify that the value of $Q_{\max }(766 \pm 76)$, maximum number of sorption site, is very high compared to $q_{e}$ (sorbed contaminant concentration). This observation is consistent with the fact that the adsorbent had a higher affinity for arsenic as attested by the observed high percent removal values (Figure 2).

Likewise, the Freundlich sorption model yielded higher values of the distribution coefficient, $k(15.1 \pm 2.76)$, and the chemical-specific quantity, $n(1.5 \pm 0.2)$, which again indicate that the adsorbent (stabilized ferralsols) has a high affinity for arsenic. This implies that within the concentration range used $(0-20 \mathrm{mg} / \mathrm{L})$ arsenic adsorption on stabilized ferralsols was not constrained by the number of sorption sites. In view of this, stabilized ferralsols should be able to effectively remove the contaminant from water sources in the study area since the highest arsenic concentration observed in the sampled water sources was just $70 \mathrm{ppb}$.

\section{Conclusions}

In the present study, arsenic was detected in $58 \%$ of water sources sampled and $41 \%$ of them had arsenic levels equal to or exceeding the Tanzania Drinking Water Quality Standards threshold value of $10 \mathrm{ppb}$. Modeling of data has shown that arsenate is more dominant than arsenite, which is the most toxic species. Arsenic mobilization is suspected to be due to oxidation of arsenopyrite after exposure of the ore to the air partly due to mining activities. The arsenic contamination problem in the study area may be aggravated in a near future by high population exposed to the contaminant, lack of reliable and safe water sources and dry weather conditions, which tend to concentrate the contaminant.

Stabilized ferralsols was capable of removing via adsorption up to $99.7 \%$ of arsenic regardless of $\mathrm{pH}$ and initial concentration. In view of this, adsorption using stabilized ferralsols may be considered to be a promising technology for removing arsenic from drinking water.

Generally, arsenic occurrence in groundwater has a large spatial and temporal variability especially in terms of species and concentration thus making it difficult to draw meaningful conclusion from a handful set of data based on only one sampling effort. It is, therefore, recommended that more comprehensive surveillance studies should be performed for proper quantification of the magnitude of the arsenic contamination problem.

Studies reported in the current paper were conducted under controlled laboratory conditions, which did not mimic actual field conditions reasonably well. In view of this, further studies involving column experiments are recommended to be conducted under actual field operating conditions which could affect adsorption efficiency such as contact time, particle size, competing species, and temperature. It is also worth investigating the possibilities of regeneration of the adsorbent.

\section{ACKNOWLEDGEMENTS}

The authors would like to register their 
appreciations to the Swedish Government for financing the study through the department for Research Co-operation (SAREC), within the Swedish International Development Agency (SIDA). The assistance of Mr. Lusako Raphael and Mr. Aldo Ndimbo in laboratory and field studies is also highly acknowledged.

\section{REFERENCES}

Bhumble DK., Keefer RF. 1994. Arsenic Mobilization and Bioavailability in Soils. In Arsenic in the Environment. Part 1: Cycling and Characterization, J. O. Nriagu (ed). Wiley and Sons: New York; 51-82.

Department of Geology 1994. Study on mercury and other heavy metal pollution in gold mining areas around Lake Victoria. (Unpublished report). University of Dar es Salaam, Dar es Salaam.

Halsey PM. 2000. Arsenic Contamination Study of Drinking Water in Nepal. PhD Thesis, Massachusetts Institute of Technology, Boston, p. 73.

Jain CK, Ali I. 2000. Arsenic: occurrence, toxicity and speciation techniques. Water Res., 34(17): 4304-4312.

Johnston R, Heijnen H. 2001. Safe water technology for arsenic removal. In Technologies for Safe Removal of Arsenic from Drinking Water, Ahmed FF, Ali MA (eds). Compilation of papers presented at the International Workshop on Technologies for Arsenic Removal from Drinking Water. Bangladesh University of Engineering and Technology and the United Nations University: Dhaka; 1-22.

Kassenga GR. 2003. Simulation of the effects of phosphate on adsorption of arsenite and arsenate on ferrihydrite matrix using a geochemical equilibrium model. Journal of Building and Land Development., 12(1-3): 42 - 54.

Korte NE, Fernando Q. 1991. A Review of arsenic(III) in groundwater. Critical Rev. Environ. Ctrl., 21: 1-39.

Kundu S, Kavalakatt SS, Pal A Ghosh SK, Mandal M, Pal T. 2004. Removal of arsenic using hardened paste of Portland cement: batch adsorption and column study. Water Res., 38: 3780-3790.

Lokuge KM, Smith W, Caldwell B, Dear K, Milton AH. 2004. The effect of arsenic mitigation interventions on disease burden in Bangladesh. Environ. Health Perspect., 112(11): 1172-1177.

Mukherjee A, Sengupta MK, Hossain MA, Ahamed S, Das B, Nayak B, Lodh D, Rahman MM, Chakraborti D. 2006. Arsenic contamination in groundwater: a global perspective with emphasis on the Asian Scenario. Journal of Health, Population and Nutrition, 24(2): 142-163.

Olisio C, Lodi A, Converti A, Borghi, MD. 2002. Removal of exhausted oils by adsorption on mixed $\mathrm{Ca}$ and $\mathrm{Mg}$ oxides. Water Res., 36(4): 899-906.

Parkhurst DL, Appelo CAJ. 1999. User's Guide to PHREEQC (Version 2). A computer program for speciation, batchreaction, one-dimensional transport, and inverse geochemical calculations. Water Resources Investigations Report, 994259, U.S. Department of Interior, Denver.

Pogany M, Davies L. 2001. Arsenic remediation of drinking water: phase II. Research experiences for undergraduates, National Science Foundation Summer Program, South Dakota School of Mines and Technology.

Smedley PL. 1996. Arsenic in rural groundwater in Ghana. J. Afr. Earth. Sci.., 22: 459-470.

Smedley PL, Kinniburgh DG. 2002. A review of the source, behaviour and distribution of arsenic in natural waters. Appl. Geoch., 17: $517-568$

Smith AH, Lingas EO, Rahman M. 2000. Contamination of drinking water by arsenic in Bangladesh: a public health emergency. Bulletin of the World Health Organization., 78(9): 1093-1103.

Smith E, Naidu R, Alston AM. 2002. Technical report on heavy metals in the environment: chemistry of inorganic arsenic in soils II (effect of phosphorus, sodium, and calcium on arsenic sorption). J. Environ. Qual., 31:557-563.

Sutcliffe JV, Petersen G. 2007. Lake Victoria: derivation of a corrected natural water level series. Hydrol. Sci. J., 52(6): 13161321.

URT (United Republic of Tanzania). 2002. Population and Housing Census. National Bureau of Statistics: Dar es Salaam. 
Vance DB. 1995. Arsenic - chemical behaviour and treatment. The National Environmental Journal, 5(3): 60-64.

Welch AH, Westjohn DB, Helsel DR, Wanty RB. 2000. Arsenic in ground water of the United States: Occurrence and geochemistry. Ground Water, 38: 589604.

Wiedemeier TH, Swanson MA, Moutoux DE, Gordon EK. 1996. Technical Protocol for
Evaluating Attenuation of Chlorinated Solvents in Groundwater. Air Force Center for Environmental Excellence, Technology Transfer Division: San Antonio.

World Health Organisation (WHO). 2001. Arsenic and Arsenic Compounds (2nd edn). Environmental Health Criteria 224, World Health Organization: Geneva. 